\title{
Somatic growth rates of hawksbill turtles Eretmochelys imbricata in a northern Great Barrier Reef foraging area
}

\author{
Ian Bell*, David A. Pike \\ School of Marine and Tropical Biology, James Cook University, Townsville Queensland 4811, Australia
}

\begin{abstract}
An understanding of the rate at which long-lived species grow is essential for determining important life history parameters, including assessments of foraging habitat quality, the time taken to reach sexual maturity, and the age at which maturity is reached. The hawksbill sea turtle Eretmochelys imbricata is a Critically Endangered species that is typically associated with coral reefs throughout the tropical oceans. Little is known about its life history through most ageclasses, especially in the western Pacific, one of the last strongholds for the species. We undertook annual surveys of a foraging population of hawksbill turtles on 13 reefs, within the far northern section of the Great Barrier Reef (GBR), from 1997 to 2008. We obtained growth rate data from 128 turtles that were recaptured once $(n=103)$, twice $(n=23)$, or 3 times $(n=2)$. The curved carapace length of recaptured turtles ranged from 61.3 to $91.4 \mathrm{~cm}(\bar{x}=79.8 \pm 7.26 \mathrm{~cm}$, mean \pm SD). Recapture intervals spanned between 11 and 120 mo (mean: 59 mo; median: 72 mo). We show that mean annual growth rates did not differ between sexes and had a non-monotonic growth pattern, reaching peak growth for both sexes within the 65 to $70 \mathrm{~cm}$ curved carapace length size-class. Growth slowed thereafter at a linear rate, to negligible growth upon reaching an adult size of $>80 \mathrm{~cm}$. Hawksbill turtles grew faster in the southern GBR, compared to those found in the far north of the reef. Understanding spatial and temporal differences in growth rates, and thus age at maturity, is an important step towards resolving life history differences among sea turtle populations.
\end{abstract}

KEY WORDS: Eretmochelys imbricata $\cdot$ Growth rate $\cdot$ Mark-recapture $\cdot$ Sea turtles $\cdot$ Sex-specific growth

\section{INTRODUCTION}

Annual survival probabilities for small-sized, immature marine turtles are typically low and increase proportionally with somatic growth until maturity is reached, after which point survivorship is high for most populations (Chaloupka \& Limpus 1997, Bjorndal et al. 2000). The tight link between body size and survival rate suggests that natural selection favours a high growth rate during early life, and that small turtles need to get large quickly. The rate at which a cohort of turtles is growing impacts the overall capacity of a population to function, and ultimately influences survival (Andrews 1982). An understand- ing of the rate at which individual animals within regional stocks are growing, and therefore maturing, is fundamental for identifying threats and, if necessary, for developing sound management strategies.

Of all species of sea turtle, hawksbill turtles Eretmochelys imbricata are the most likely to be associated with coral reef habitat (Witzell 1983). Australia's Great Barrier Reef (GBR) is the largest reefal system in the world, being approximately $2000 \mathrm{~km}$ in length, containing some 3800 individual reefs and islands, and encompassing an area of approximately $347800 \mathrm{~km}^{2}$ (Hopely et al. 2007). This reef system supports globally important $E$. imbricata foraging populations, but little is known about the foraging ecology of marine 
turtles generally, especially in the northern GBR. The limited information on feeding aggregations resident in the northern GBR (e.g. Limpus \& Miller 2000) does not necessarily reflect a lack of turtles, but merely that the coast and offshore islands are remote and access to conduct surveys is limited. E. imbricata are known to be present in the region, but to date no specific locations have been identified as supporting high densities of feeding aggregations comprising all ageclasses (Witzell \& Banner 1980, Limpus 1992b, Robins 1995, Chaloupka \& Limpus 1997).

Because Eretmochelys imbricata rely so heavily on resources supplied by coral reef ecosystems, they make an ideal proxy indicator for measuring the health of, or detecting change in, those environmental systems. For example, slower relative somatic growth rates displayed within one cohort as compared to another may be an indicator of suboptimal conditions within a feeding habitat (Balazs 1982); conversely, faster growth rates may reflect plentiful resources (Hilty \& Merenlender 2000). Growth rate data also can elucidate other important demographic parameters, such as the time taken to reach maturity, overall turtle health, and geographic differences in productivity between spatially distinct foraging habitats (Limpus 1979, Klinger 1995, Limpus \& Chaloupka 1997).

Obtaining robust, long-term data on free ranging Eretmochelys imbricata is not without its challenges, and helps explain why a paucity of information exists. Foraging areas are remote and difficult to access, turtles are cryptic, and repeated captures of the same turtle over temporally distinct periods can be extremely difficult (Chaloupka \& Musick 1997). Despite these challenges, repeated measurements from a range of age-classes over extended time periods are clearly needed to serve as baseline data that allow detection of growth trends over time and space.

Here we present a comprehensive analysis of the temporal growth dynamics of hawksbill turtles resident on reefs of the Howick Group of islands located in the far northern section of the GBR, Australia (Fig. 1). We compare our findings to published work from the southern GBR to better understand growth in a population that spans a considerable geographic range and environmental conditions. Understanding the growth dynamics of this species and how it varies geographically will aid in predicting the long-term viability of the western Pacific hawksbill metapopulation, which is subject to numerous anthropogenic threats including continued harvesting pressures (Chaloupka 2002, 2004). The present study provides the first growth data for a major hawksbill foraging population in the western Pacific.

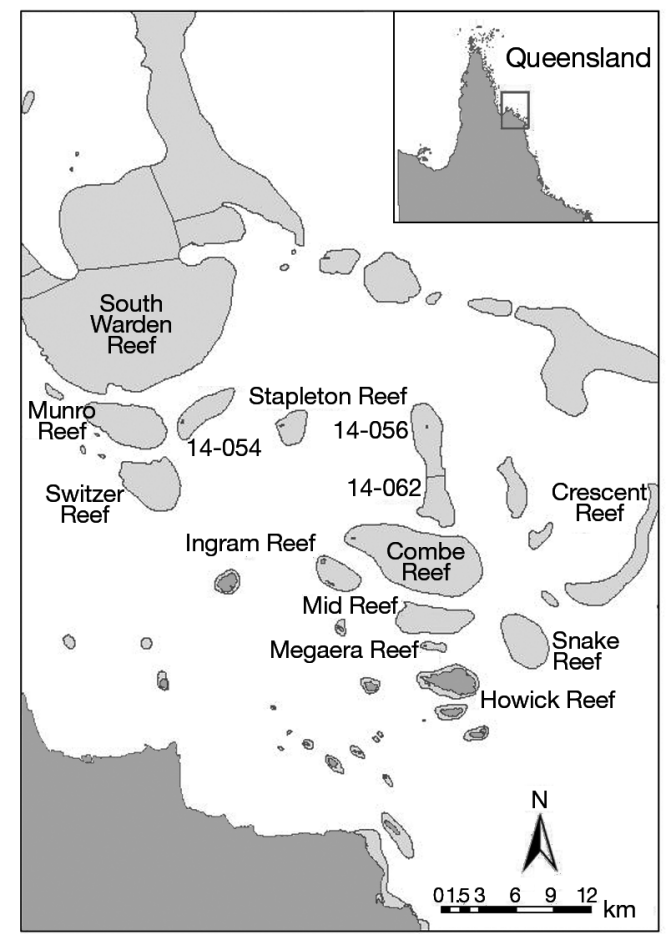

Fig. 1. Location of the Howick Group of reefs in the northern section of the Great Barrier Reef (GBR) Marine Park, north Queensland, Australia. Northern Queensland is depicted in the inset, and the focal reefs used in the present study are named in the main panel

\section{MATERIALS AND METHODS}

A total of 8 annual turtle capture-recapture sampling events were undertaken between 1997 and 2008, at the Howick Group of islands on the GBR, Australia (Fig. 1). We used a rodeo capture technique to opportunistically catch turtles, which were marked with 2 uniquely coded titanium tags, measured, and released (Limpus \& Reed 1985). Tag loss for similar mark-recapture programs within the GBR was inconsequential (Limpus 1992a) and is not accounted for here. The final dataset included initial body size and subsequent growth records for 119 female and 9 male turtles, spanning the post-neritic habitat recruitment phase, with body sizes ranging from ca. 40 to $95 \mathrm{~cm}$ curved carapace length (CCL). Capturerecapture profiles for each turtle included (1) CCL at first capture and at subsequent recapture $(\mathrm{cm})$; (2) sex and maturity status by age-class, determined using laparoscopic examination of reproductive organs (for detailed information on the criteria used to determine sex, see Limpus \& Reed 1985, Limpus et al. 1994); (3) year of first capture; and (4) years at large since first capture or previous recapture. Only 
turtles with recapture intervals $>11$ mo were used to minimize measurement error on growth estimation.

CCL was taken as the mid-line distance between the leading edge of the nuchal scute and the greatest extension of the post-vertebral scute, measured using a flexible fibreglass tape measure (to $0.1 \mathrm{~cm}$; Limpus et al. 1994). Absolute growth rates were derived from 233 capture-recapture profiles following the method of Chaloupka \& Limpus (1997), with both negative and zero growth rates included in final analyses (Chaloupka \& Musick 1997, Limpus \& Chaloupka 1997). Annual growth rate was calculated as $\left(\mathrm{CCL}_{\text {final }}-\mathrm{CCL}_{\text {initial }}\right) /$ recapture interval in years. Mean values are followed by the standard deviation (SD).

\section{Sampling design and statistical approach}

We used a mixed longitudinal sampling design (sampling with partial replacement; see full details in Chaloupka \& Limpus 1997). We modelled the relationship between the absolute growth rates recorded for each female and specific growth rate predictors, or explanatory covariates, using a generalized additive modelling (GAM) approach (see Hastie \& Tibshirani 1990). This nonparametric regression model allows (l) flexible specification of error and link functions, and (2) arbitrary specification of the functional form for each predictor included in the regression model. Our model identified the nonlinear relationship between the response variable (annual growth rate) and the continuous covariates (year, mean body size, time at large), ultimately deriving size-specific growth rates for turtles of unknown age. We included the calendar year of the growth record as a covariate to account for the implicit time series sample design inherent in all mark-recapture studies (Bjorndal et al. 2000). This accounts for changes in growth rate caused by environmental factors or age (cohort) effects. These effects cannot be separated using our dataset because we do not know the ages of turtles in the present study (as is the case with most studies of wild sea turtles). The mean body size covariate was based on the arithmetic mean between CCL at initial capture and subsequent recapture. Mean size is the appropriate metric for describing size-specific growth for shorter time intervals, during which there is a greater likelihood of linear growth (Chaloupka \& Musick 1997). However, when recapture intervals span longer timeframes, mean size calculations may be inappropriate due to nonlinearity (Chaloupka \& Limpus 1997, Scott et al 2011). In the present study, recapture intervals ranged from 11 to 120 mo, so recapture interval was included as a covariate to account for potential bias caused by variation in sampling intervals. Our GAM used an identity link, a robust quasi-likelihood error function, and a fairly stiff cubic smoothing spline to estimate nonlinear relationships between the response variable and continuous covariates. The quasi-likelihood function accounted for any error associated with using multiple growth intervals for individual turtles, and is dependent upon the empirical mean-variance relationship generated from the data (Hastie \& Tibshirani 1990). Cubic smoothing splines identify underlying growth functions while minimizing the effects of small sample size and outliers (Chaloupka \& Limpus 1997).

We used an ANOVA to determine whether growth rates differed between immature male and female Eretmochelys imbricata in the northern GBR. To compare female growth rates between northern and southern GBR conspecifics (using southern GBR data from Chaloupka \& Limpus 1997), we used an ANCOVA with mean body size as the covariate, annual growth rate as the dependent variable, and region as the factor.

\section{RESULTS}

\section{Recapture intervals and absolute growth rates}

We captured a total of 665 individual Eretmochelys imbricata from 1997 to 2008, and obtained growth data from 128 turtles (103 recaptured once, 23 recaptured twice, and 2 recaptured 3 times). Recapture intervals ranged from 11 to 120 mo (mean: 59 mo; median: $72 \mathrm{mo}$ ). Of the turtles that were recaptured, the CCL at the first capture ranged from 61.3 to $91.4 \mathrm{~cm}$ $(\bar{x}=79.8 \pm 7.26 \mathrm{~cm}$, mean $\pm \mathrm{SD}$; Table 1$)$. Multiple turtles $(\mathrm{n}=111)$ had CCLs $<61.3 \mathrm{~cm}$, but none of these turtles was recaptured a second time. Mean annual growth rate data reflected a non-monotonic growth pattern, reaching a peak for both sexes within the 65 to $70 \mathrm{~cm}$ CCL size class, and from that point slowing at a linear rate to negligible growth upon reaching adulthood size of $>80 \mathrm{~cm}$ CCL.

\section{Growth model}

The small number of male turtles for which growth rate data were available $(\mathrm{n}=9)$ precluded reliable model fitting, and thus our GAM analysis incorporates females only. The GAM nonparametric regres- 
Table 1. Eretmochelys imbricata. Summary of parameter estimates for a generalized additive model (GAM) with a robust quasi-likelihood error term and cubic smoothing splines (nonparametric degrees of freedom, npar df $=3$ ) fitted to turtle growth rates. Null deviance $=129.94$, null $\mathrm{df}=114$, residual deviance $=77.44$, residual $\mathrm{df}=101$, quasi-likelihood dispersion parameter $=0.77, R^{2}=(129.94-77.44) / 215.46=0.68 .{ }^{*}$ Statistically significant effect

\begin{tabular}{|c|c|c|c|c|c|c|c|}
\hline \multirow[t]{2}{*}{ Factor } & \multirow[t]{2}{*}{ Estimate } & \multirow{2}{*}{$\begin{array}{l}\text { Asymptotic } \\
\text { SE }\end{array}$} & \multirow[t]{2}{*}{$t$ ratio } & \multirow[t]{2}{*}{ Prob $(t)$} & \multicolumn{3}{|c|}{ Nonlinear effects (nonparametric) } \\
\hline & & & & & npar df & npar $F$ & $\operatorname{Prob}(F)$ \\
\hline Intercept & 11.77 & 83.16 & 0.14 & 0.890 & & & \\
\hline Mean size & -0.04 & 0.02 & -2.26 & $0.026^{*}$ & 3 & 4.61 & $0.005^{*}$ \\
\hline Year & -0.01 & 0.04 & -0.09 & 0.930 & 3 & 1.57 & 0.200 \\
\hline Recapture interval & -0.11 & 0.03 & -3.71 & $0.0003^{*}$ & 3 & 0.97 & 0.410 \\
\hline Maturity status & -0.45 & 0.20 & -2.21 & $0.029^{*}$ & & & \\
\hline
\end{tabular}

Table 2. Eretmochelys imbricata. Pooled annual absolute growth increments recorded for individuals recaptured within the same age-class, and for turtles that had matured to another age-class between recaptures. Note that in some cases growth values are negative, which is suggestive of measurement error

\begin{tabular}{|lccccc|}
\hline \multicolumn{2}{|c}{ Age-class at capture } & Sex & \multicolumn{3}{c|}{ Growth rate yr ${ }^{-1}(\mathrm{~cm})$} \\
1st & Subsequent & & Mean & Range & $\mathrm{n}$ \\
\hline Juvenile & Juvenile & Female & 1.76 & $0.5-3.2$ & 9 \\
Juvenile & Pubescent & Female & 1.79 & $0.1-3.1$ & 3 \\
Pubescent & Pubescent & Male & 1.28 & $-0.6-4.7$ & 5 \\
& & Female & 1.25 & $-0.4-5.6$ & 31 \\
Pubescent & \multirow{2}{*}{ Adult } & Male & 0.90 & $-0.6-1.2$ & 2 \\
& & Female & 0.71 & $-0.1-5.4$ & 23 \\
Adult & \multirow{2}{*}{ Adult } & Female & 0.17 & $-0.9-2.7$ & 45 \\
& & & & & \\
\hline
\end{tabular}

sion models fit the data well, as indicated by small residual deviances relative to residual degrees of freedom and the nonparametric $\mathrm{R}^{2}$ values, given the relatively small sample sizes (Table 1 ). Growth rates were dependent upon mean body size, maturity status, and recapture interval, but not year (Table 1).

\section{Effect of body size on growth}

Mean carapace length had a significant effect on expected growth rates $\left(\mathrm{CCL}, \mathrm{cm} \mathrm{yr}^{-1}\right.$ ) in the present study area (Tables 1 \& 2). Size-specific growth rate was coupled with maturity status and had a monotonic decreasing function, falling steadily from slightly under $2.0 \mathrm{~cm} \mathrm{yr}^{-1}$ for immature-sized turtles $(<62 \mathrm{~cm}$ CCL) to close to zero annual growth for adult turtles (>92 cm CCL; Fig. 2). This monophasic growth rate function, which shows a single peak during pubescence followed by a declining growth rate through adulthood, is apparent in other sea turtle populations (Chaloupka \& Musick 1997).

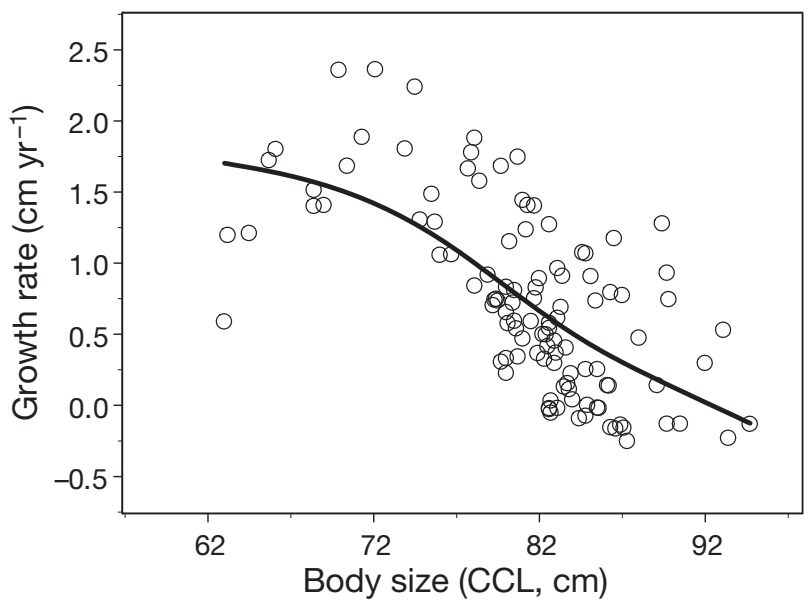

Fig. 2. Estimated size-specific growth rate function for hawksbill turtles resident in northern Great Barrier Reef foraging grounds, shown in relation to body size (curved carapace length [CCL] in $\mathrm{cm}$ ). Fitted growth rate values are from the generalized additive model (GAM) model, and the curve is a cubic B-spline smoother fitted to the GAM model values to highlight the underlying size-specific growth rate function

\section{Effect of maturity status on growth}

The maturity status of turtles (immature, mature) also had a significant effect on growth rates. Immature turtles, irrespective of sex, grew considerably faster than mature turtles, even though many adults (assessed by laparoscopy) were no larger than many large immature turtles (Fig. 3a). Somatic growth rates were faster and monotonic in immature turtles of both sexes, and declined to negligible levels $\left(<0.1 \mathrm{~cm} \mathrm{yr}^{-1}\right)$ when turtles reached sexual maturity.

\section{Effect of sex on growth}

We found no significant difference in absolute growth rates between the sexes in immature turtles 


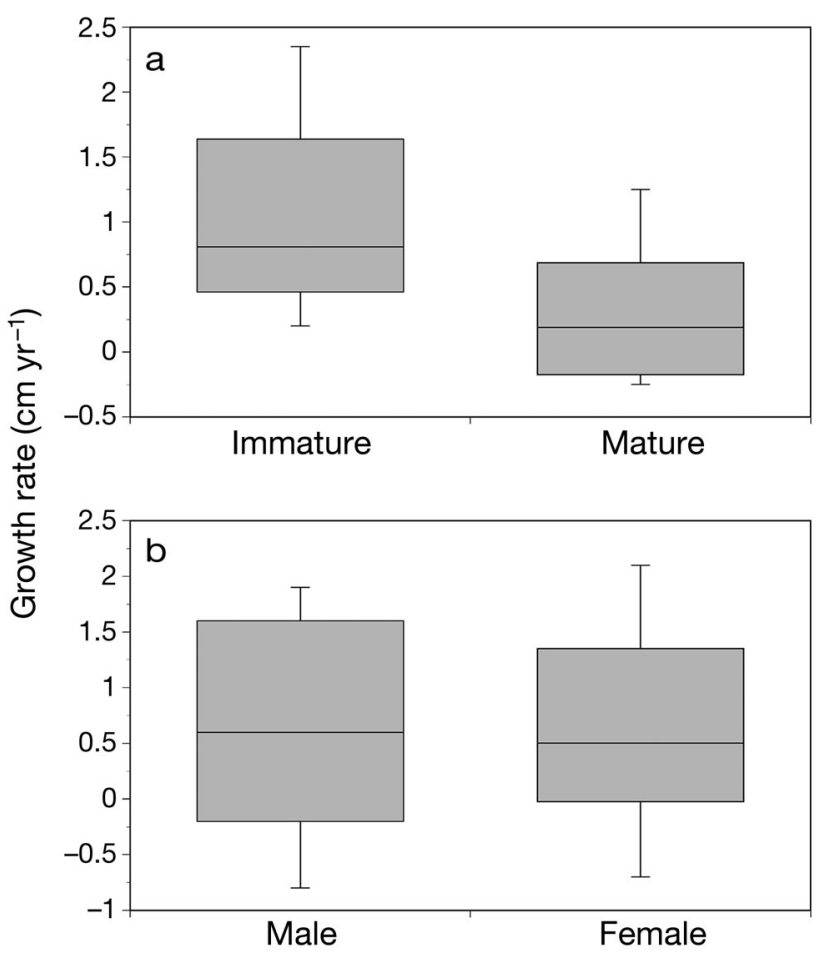

Fig. 3. Growth rates $\left(\mathrm{cm} \mathrm{yr}^{-1}\right)$ of (a) immature and mature hawksbill turtles, and (b) male and female hawksbill turtles. Boxes depict the median and first and third quartiles, while the whiskers depict the standard deviation (SD)

$\left(\right.$ ANOVA $_{i} F_{1,75}=0.06, \mathrm{p}=0.82 ;$ the low sample sizes of males precluded comparisons among adults; Table 2). Similar sex-specific growth functions of immature turtles presented here (Fig. 3b) would not result in sexual dimorphism between mature turtles. However, the mean CCL for all adult males $(\bar{x}=$ $82.5 \mathrm{~cm}$; range: 74.6 to $87.5 \mathrm{~cm} ; \mathrm{n}=17$ ) and females $\left(\bar{x}=84.9 \mathrm{~cm}_{\text {; }}\right.$ range: 74.5 to $\left.97.0 \mathrm{~cm}_{i} \mathrm{n}=242\right)$ indicated that males were on average $2.4 \mathrm{~cm}$ smaller than adult females. If growth rates are in fact similar for each sex, then the time it takes to reach maturity may be longer for females.

\section{Effect of recapture interval on growth}

Recapture interval had a significant impact on growth across all age-classes and both sexes (Table 2, Fig. 4). While mean body size is an appropriate metric for indexing size-specific growth, there is an assumption that growth within a sampling interval is linear (Chaloupka \& Limpus 1997, Scott et al. 2011). This assumption is reasonable if short sampling intervals are used.

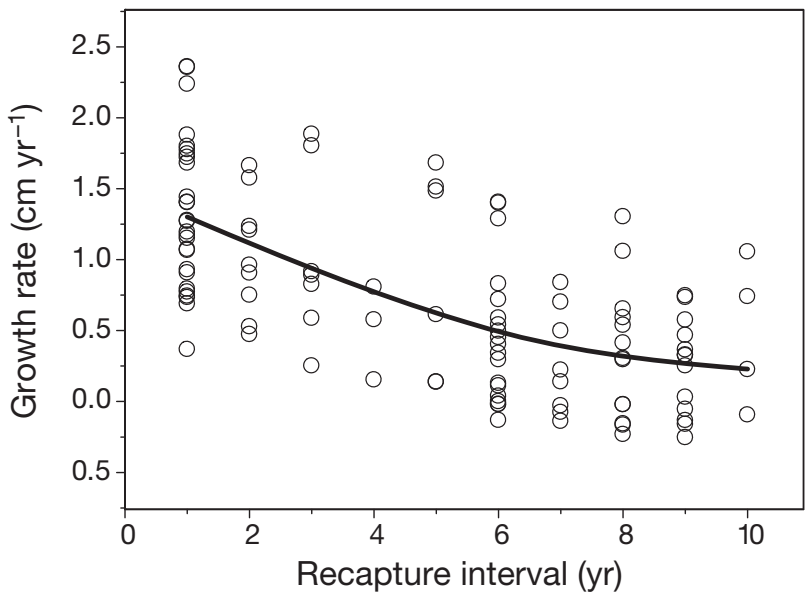

Fig. 4. Effect of recapture intervals on growth rates of Eretmochelys imbricata

\section{Growth rates between southern and northern populations}

Growth rates of female hawksbill turtles differed significantly between populations (ANCOVA with mean body size as the covariate; $F_{1,156}=7.70, \mathrm{p}=$ 0.006; Fig. 5). Overall, females from the southern GBR grew significantly faster $\left(1.29 \mathrm{~cm} \mathrm{yr}^{-1}\right)$ than conspecifics in the northern GBR $\left(0.90 \mathrm{~cm} \mathrm{yr}^{-1}\right)$.

\section{DISCUSSION}

The growth rates we present for hawksbill turtles foraging on reefs of the Howick Group in the northern GBR are the first detailed data for mature-aged hawksbills in the western Pacific generally, and for the northern GBR specifically. The major findings of our long-term study are: (1) turtles displayed nonmonotonic growth rates, with maximum growth rates observed within the 65 to $70 \mathrm{~cm}$ CCL size class, declining to zero-growth by mature-aged turtles; (2) no significant year effect on growth rates between sexes of similar age-classes; and (3) relatively slow age-specific growth, likely to result in turtles taking 3 to 4 decades to reach sexual maturity. Turtles in general mature much later than other reptiles (Scott et al. 2011), and hawksbills follow this trend.

Monotonic growth also has been observed in the southern GBR, with turtles displaying non-monotonic growth though the juvenile age-class, with rates peaking at approximately $60 \mathrm{~cm}$ CCL and declining to negligible growth through to maturity (Chaloupka \& Limpus 1997). The primary capture of 111 turtles 


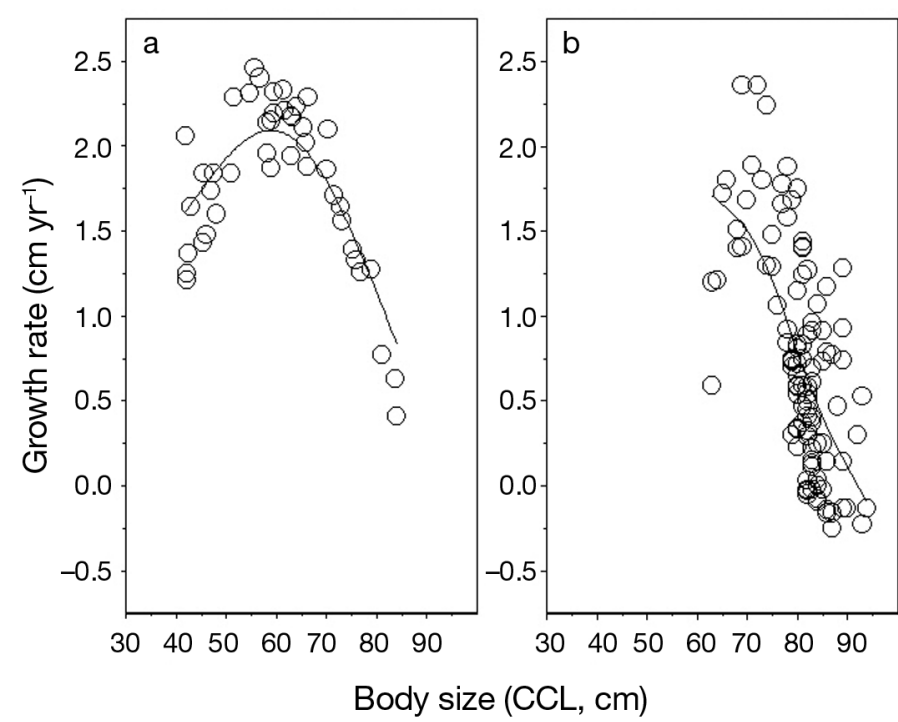

Fig. 5. Comparison of female hawksbill size-specific growth rates between (a) southern GBR populations (from Chaloupka \& Limpus 1997) and (b) northern GBR populations (present study). Data from the southern GBR were interpolated from

Chaloupka \& Limpus (1997) using the software xyExtract

with CCLs $<61.3 \mathrm{~cm}$ (the smallest size-class of recaptured turtles in the present study) refutes the suggestion by Limpus (1992a) that hawksbills are undertaking developmental migrations away from the southern GBR to populate reefs in the northern GBR. In fact, small turtles (33.5 to $61.0 \mathrm{~cm}$ CCL) were caught during every survey period, but simply were unable to be recaptured in successive years to record growth rates.

\section{Estimating hawksbill turtle age to maturity}

The use of biometric parameters such as somatic growth rates to develop these estimates are complex functions comprising time, age, year, and cohort effects for any species (Chaloupka 2002). A confounding aspect of any marine turtle age-to-maturity study is determining the age at which animals recruit to benthic foraging areas as juvenile turtles (Troeng \& Chaloupka 2007). After leaving their nesting beaches in the Solomon-Bismarck Sea, post-hatchling-sized hawksbills spend an unknown period of time, possibly 7 to $10 \mathrm{yr}$ (Velez-Zuazo et al. 2008) in an epi-pelagic existence before reappearing as $\sim 60 \mathrm{~cm}$ CCL juvenile turtles at northern GBR foraging areas (Walker 1994). The mean size of juvenile hawksbills found in the Howick group was larger than this (at $69.6 \mathrm{~cm} \mathrm{CCL}$ ), possibly indicating a longer pelagic phase or an intermediary developmental phase, as proposed by Limpus (1992b).

Age-specific growth rates (Fig. 3a), indicate that immature hawksbills were growing at the fastest rates upon recruitment to the Howick Group. However, this may be confounded by the fact that the 111 recaptured turtles were larger than the smallest turtles captured only once. Our inability to recapture small-sized turtles may simply reflect the difficulty in recapturing these turtles.

Assuming that the duration of the oceanic phase for the northern GBR stock is similar to other conspecifics ( $10 \mathrm{yr}$; Bowen et al. 2007), and that growth rate declines steadily following a maxima reached by immature turtles, our data indicate that it will take several decades to reach sexual maturity. The difficulty in using such growth functions for this purpose is the lack of conclusive growth criteria to indicate the onset of maturity. One criterion in the absence of maturity rate functions is the size at which the onset of negligible growth $\left(\sim 0.2 \mathrm{~mm} \mathrm{yr}^{-1}\right)$ is apparent (Limpus \& Chaloupka 1997). This is $\sim 82 \mathrm{~cm}$ CCL for the Howick Group foraging population (Fig. 5). Turtles in general reach maturity at a much older age than other reptiles (Scott et al. 2011), and Eretmochelys imbricata appear to follow this trend. Assuming an oceanic phase duration of $10 \mathrm{yr}$ (Bowen et al. 2007), we estimate the expected age at maturity to be between 20 and 40 yr for the Howick Group population, which is consistent with the estimate of $>30 \mathrm{yr}$ for a southern GBR foraging aggregation (Limpus 1992b, Chaloupka \& Limpus 1997).

\section{Growth rates between sexes}

Size-specific growth functions were not significantly different between the sexes, with immature females and males growing at similar rates. This result implies the absence of adult size dimorphism, and suggests that males and females reach maturity at a similar size or age. Nietschmann (1981) proposed adult size dimorphism existed within a mixed-stock of hawksbills in Nicaraguan waters, but Limpus (1992b) has questioned those data. While the sexspecific growth functions presented here indicate that foraging adult male turtles within the northern GBR are likely to be of a similar size as mature females, mean CCL data indicate otherwise. Although we acknowledge that a small adult male recapture sample may confound a comparison between adults, an approximate $2.4 \mathrm{~cm}$ difference in the mean CCL between sexes indicates that females 
clearly are larger. This, in turn, may indicate that the time taken to reach sexual maturity may be substantially longer for females than males.

\section{Growth rates by age-class}

We found that the mean CCL of adult female Eretmochelys imbricata declined by $-0.06 \mathrm{~cm} \mathrm{yr}^{-1}$ over the monitoring period. This indicated that growth is negligible and the carapace trailing edge abrades at a rate that exceeds growth, once maturity is reached. Data describing the rate at which adult hawksbills grow within the GBR are lacking; however, nesting studies provide more information. For example, Dobbs et al. (1999) reported that turtles returning to nest on Milman Island after a 3 yr absence grew an average of $0.27 \pm 0.19 \mathrm{~cm} \mathrm{yr}^{-1}$ (range: 0.0 to $0.7 \mathrm{~cm}, \mathrm{n}=22$ ). The nominal growth rates of adult turtles in the Howick Group are similar to those reported in other studies (e.g. Limpus 1992b, Loop et al. 1995, Pilcher \& Ali 1999); however, we think these results should be interpreted with caution. Standard errors (SE) reported in each of these studies were greater than the respective means, raising questions about the usefulness of the statistical values. Generally, however, as in other marine turtles, adult hawksbill growth is consistently slow, if at all detectable, once sexual maturity has been reached.

Immature Eretmochelys imbricata within the Howick Group had a mean growth rate of $1.26 \mathrm{~cm} \mathrm{yr}^{-1}$ CCL, which was significantly less than the growth rates for the same age-classes reported for the southern GBR, in the Northern Territory of Australia, in the
Bahamas, and in Western Samoa (Table 3). While limited data exist, a monotonic decreasing size-specific growth rate function for immature hawksbills in the Howick Group is similar to that proposed for a western Atlantic-Caribbean resident green turtle population by Bjorndal \& Bolten (1988) and Boulon (1994). A monotonic decreasing growth function suggests the absence of a growth spurt and a von Bertalanffy size-at-age growth function.

\section{Growth rates among regions}

The growth rates of regionally distinct hawksbill cohorts, as with other species of marine turtle, are thought to be influenced by a variety of genotypic factors such as body size and sex (Boulon \& Frazer 1990, Chaloupka \& Limpus 1997), as well as phenotypic or environmental factors such as food quality and quantity, resource competition, predation pressure, ambient temperature, and latitude (León \& Bjorndal 2002). The ultimate effects of the interplay between these physiological or environmental factors are not yet fully understood (Birse \& Davenport 1987). However, different growth rates of individuals exploiting sites of varying quality within a region may have profound effects on other aspects of population dynamics, such as annual survival probabilities, the rate of sexual maturation, and remigration periodicity (Diez \& van Dam 2002, Casale et al. 2011).

Diez \& van Dam (2002) speculated that variations in food abundance and quality were responsible for the different growth rates they found between feeding sites within the Caribbean. However the differ-

Table 3. Eretmochelys imbricata. Growth rates (shown by $10 \mathrm{~cm}$ size-class increments) from turtles within the Howick Group (present study) and from other published studies. Data are presented as mean growth rate \pm standard deviation (SD), followed by the range in parentheses and the number of recaptures. Turtle body size varied among studies, and in some cases data were not available (na)

\begin{tabular}{|c|c|c|c|c|c|c|c|}
\hline \multirow[t]{2}{*}{ Location, study } & \multirow{2}{*}{$\begin{array}{c}\text { Recapture } \\
\text { interval (mo) }\end{array}$} & \multicolumn{6}{|c|}{ - Curved carapace length (CCL) size-class (cm) - } \\
\hline & & $30-40$ & $40-50$ & $50-60$ & $60-70$ & $70-80$ & $80-90$ \\
\hline $\begin{array}{l}\text { Howick Group, northern } \\
\text { Great Barrier Reef } \\
\text { (present study) }\end{array}$ & $11-120$ & na & na & na & $\begin{array}{c}2.5 \\
(0.8-4.7), 3\end{array}$ & $\begin{array}{c}0.5 \\
(-0.2-1.2), 2\end{array}$ & $\begin{array}{c}0.6 \\
2(-0.6-4.8), 3\end{array}$ \\
\hline $\begin{array}{l}\text { Southern Great Barrier Reef } \\
\text { (Limpus 1992b) }\end{array}$ & $>11$ & na & $\begin{array}{c}1.4 \pm 0.5 \\
(0.7-2.2), 6\end{array}$ & $\begin{array}{c}2.17 \pm 0.88 \\
(0.36-3.53), 10\end{array}$ & $\begin{array}{c}1.9 \pm 0.6 \\
(0.5-2.7), 13\end{array}$ & $\begin{array}{l}1.3 \pm 1.1 \\
(0-2.3), 6\end{array}$ & $\begin{array}{c}0.7 \pm 0.8 \\
(-0.3-1.7), 6\end{array}$ \\
\hline $\begin{array}{l}\text { Northern Territory } \\
\text { (Whiting \& Guinea 1998) }\end{array}$ & $16-61$ & $\begin{array}{c}3.0 \pm 1.1 \\
(1.4-4.2), 7\end{array}$ & $\begin{array}{c}2.7 \pm 1.1 \\
(0.7-5.6), 21\end{array}$ & $\begin{array}{c}2.7 \pm 0.8 \\
(1.8-4.7), 23\end{array}$ & $\begin{array}{c}1.7 \pm 1.1 \\
(0.2-3.5), 11\end{array}$ & na & na \\
\hline $\begin{array}{l}\text { Western Samoa } \\
\text { (Grant et al. 1997) }\end{array}$ & na & na & $\begin{array}{l}4.5 \pm 2.1 \\
(3.0-5.9)\end{array}$ & na & na & na & na \\
\hline $\begin{array}{l}\text { Caribbean } \\
\text { (Bjorndal \& Bolton 1988) }\end{array}$ & na & $\begin{array}{l}15.7 \\
\text { (na), } 1\end{array}$ & $\begin{array}{c}5.9 \\
\text { (na), } 1\end{array}$ & na & $\begin{array}{c}1.8 \\
\text { (na), } 3\end{array}$ & na & na \\
\hline
\end{tabular}


ential somatic growth rates displayed by immature Eretmochelys imbricata found foraging in spatially distinct regions within the same ecosystem, such as in the northern and southern GBR (Limpus 1992a), were more likely to be an artifact of age-related growth. The foraging E. imbricata cohort described in the southern GBR was primarily sub-pubescent, and displayed a rapid growth, post-recruitment to a reef from an epi-pelagic environment. Growth peaked and subsequently slowed upon reaching approximately $60 \mathrm{~cm}$ CCL.

\section{Abiotic factors and density dependence effects that may influence Eretmochelys imbricata growth rates}

Abiotic factors, including water temperature, salinity, $\mathrm{pH}$, and turbidity, could increase or decrease metabolic rate or alter forage quality, thereby influencing growth. Additionally, localised foraging population densities could put pressure on limited resources, further complicating the suite of factors that may interact to influence hawksbill growth rates. Carrillo et al. (1999) demonstrated the effects of water temperature on growth rates if food was not a limiting factor (in captive situations), and detected effects of sea temperature on hawksbill growth rates between different regions. As with any free-ranging, long-lived reptile-and given the stochastic nature of forging environments-various factors are expected to affect growth rates over an individual's lifetime and will likely defy accurate quantification. However, understanding the interaction of these variables is not essential to be able to predict population parameters such as growth rates, mean age to maturity, and reproductive periodicity.

While it was beyond the scope of this study to determine if the density of Eretmochelys imbricata found foraging on reefs of the Howick Group was determined by the dietary resources available, these reefs support the highest known numbers hawksbill turtles within the GBR, and this warrants further exploration. Other studies have shown that foraging densities can differ greatly between sites (e.g. León \& Diez 1999, Chaloupka \& Limpus 2001). For example, at Monito Island in the Caribbean, where E. imbricata somatic growth rates are some of the fastest reported, the density of immature hawksbills in the 'foraging aggregation' (i.e. individuals of different genotypes from throughout the region) is also one of the highest known (Diez \& van Dam 2002). This would suggest an inverse relationship between population density and somatic growth rates in some areas. To explore this question, studies at specific sites along the GBR will be required to monitor turtle density and habitat quality over periods of 'years' (preferably at least decades), similar to studies undertaken by Bjorndal et al. (2000) at foraging areas of immature Chelonia mydas in the Bahamas.

\section{CONCLUSION}

Growth rates can be used as reliable proxy indicators of overall turtle population (and ecosystem) health, and provide a baseline with which to compare the quality of, or change in, foraging habitat condition. In addition, growth rate data are an essential component of population models currently being used as conservation management tools. The fact that in several western Pacific countries, including the Solomon Islands and Papua New Guinea, eggs and animals are still harvested for consumption and sale (Kinch \& Burgess 2009) highlights this point. Collecting additional growth rate data on hawksbill turtles from the GBR should be a priority for government conservation management agencies (Environment Australia 2003, IUCN 2003, Godfrey \& Godley 2008) because such data are lacking for most western Pacific foraging populations.

Acknowledgements. We thank the Earthwatch Institute for their long-term support financial support and for providing volunteer staff. This work would not have been possible without the support of the many volunteers who unselfishly devoted time and energy to our field work at the Howick Group. We thank Graeme Hays for valuable comments on an earlier draft.

\section{LITERATURE CITED}

Andrews RM (1982) Patterns of growth in reptiles. In: Gans C, Pough FH (eds) Biology of the reptilia, Vol 13: Physiology D. Academic Press, London, p 273-320

Balazs GH (1982) Growth rates of immature green turtles in the Hawaiian archipelago. In: Bjorndal KA (ed) Biology and conservation of sea turtles. Smithsonian Institute Press, Washington, DC

Birse RF, Davenport J (1987) A study of gut functioning of young loggerhead sea turtles, Caretta caretta L. at various temperatures. Herpetol J 1:170-175

Bjorndal KA, Bolten AB (1988) Growth rates of immature green turtles, Chelonia mydas, on feeding grounds in the southern Bahamas. Copeia 1988:555-564

Bjorndal KA, Bolten AB, Chaloupka MY (2000) Green turtle somatic growth model: evidence for density-dependence. Ecol Appl 10:269-282

Boulon RH (1994) Growth rates of wild juvenile hawksbill turtles, Eretmochelys imbricata, in St. Thomas, United States Virgin Islands. Copeia 1994:811-814

Boulon RH Jr, Frazer NB (1990) Growth of wild juvenile 
Caribbean green turtles, Chelonia mydas. J Herpetol 24: 441-445

Bowen BW, Grant WS, Hillis-Starr Z, Shaver DJ, Bjorndal KA, Bolten AB, Bass AL (2007) Mixed stock analysis reveals the migrations of juvenile hawksbills, Eretmochelys imbricata in the Caribbean Sea. Mol Ecol 16:49-60

Carrillo CE, Webb GJW, Manolis SC (1999) Hawksbill turtles (Eretmochelys imbricata) in Cuba: an assessment of the historical harvest and its impacts. Chelonian Conserv Biol 3:264-280

Casale P, Mazaris AD, Freggi D (2011) Estimation of age at maturity of loggerhead sea turtles Caretta caretta in the Mediterranean, using length-frequency data. Endang Spec Res 13:123-129

Chaloupka M (2002) Stochastic simulation modelling of southern Great Barrier Reef green turtle population dynamics. Ecol Model 148:79-109

Chaloupka M (2004) Exploring the metapopulation dynamics of the southern Great Barrier Reef green sea turtle stock and the possible consequences of sex-biased local harvesting. In: Akçakaya H, Burgman M, Kindvall O, Wood C, Sjogren-Gulve P, Hattfield J, McCarthy M (eds) Species conservation and management: case studies. Oxford University Press, New York, NY, p 30-31

> Chaloupka M, Limpus CJ (1997) Robust statistical modelling of hawksbill sea-turtle growth rates (southern Great Barrier Reef). Mar Ecol Prog Ser 146:1-8

Chaloupka M, Limpus CJ (2001) Trends in the abundance of sea turtles resident in southern Great Barrier Reef waters. Biol Conserv 102:235-249

Chaloupka MY, Musick JA (1997) Age, growth, and population dynamics. In: Lutz P, Musick JA (eds) The biology of sea turtles. CRC Press, Boca Raton, FL, p 233-276

> Diez CE, van Dam RP (2002) Habitat effect on hawksbill turtle growth rates on feeding grounds at Mona and Monito Islands, Puerto Rico. Mar Ecol Prog Ser 234:301-309

Dobbs KA, Miller JD, Limpus CJ, Landrey AM Jr. (1999) Hawksbill turtle, Eretmochelys imbricata, nesting at Milman Island, northern Great Barrier Reef, Australia. Chelonian Conserv Biol 3:344-361

Environment Australia (2003) Recovery plan for marine turtles in Australia. Biodiversity Group, Environment Australia, Canberra

Godfrey MH, Godley BJ (2008) Seeing past the red-flawed IUCN global listings for sea turtles. Endang Spec Res 6:155-159

Grant GS, Craig P, Balazs GH (1997) Notes on juvenile and green turtles in American Samoa. Pac Sci 51:48-53

Hastie T, Tibshirani R (1990) Generalized additive models: some applications. J Am Stat Assoc 82:371-386

Hilty J, Merenlender A (2000) Faunal indicator taxa selection for monitoring ecosystem health. Biol Conserv 92:185-197

Hopely D, Smithers SG, Parnell K (2007) The geomorphology of the Great Barrier Reef, development, diversity and change. Cambridge University Press, New York

IUCN 2003 (2003) IUCN red list of threatened species. World Conservation Union, Gland. www.redlist.org, accessed 7 January 2010

Kinch J, Burgess EA (2009) An assessment of the trade in hawksbill turtles in Papua New Guinea. Traffic 22:63-72

Klinger RC (1995) Age and growth of loggerhead turtles (Caretta caretta) from Chesapeake Bay. Copeia 1995: 204-209

León YM, Bjorndal KA (2002) Selective feeding in the hawksbill turtle, an important predator in coral reef ecosystems.

Editorial responsibility: Hans Heinrich Janssen,

Oldendorf/Luhe, Germany
Mar Ecol Prog Ser 245:249-258

León YM, Diez CE (1999) Population structure of hawksbill turtles on a foraging ground in the Dominican Republic. Chelonian Conserv Biol 3:230-236

Limpus CJ (1979) Notes on growth rates of wild turtles. Mar Turtle Newsl 10:3-5

Limpus CJ (1992a) Estimation of tag loss in marine turtle research. Aust Wildl Res 19:457-469

Limpus CJ (1992b) The hawksbill turtle, Eretmochelys imbricata, in Queensland: population structure within a southern Great Barrier Reef feeding ground. Aust Wildl Res 19: 489-506

Limpus CJ, Chaloupka MY (1997) Nonparametric regression modelling of green sea turtle growth rates. Mar Ecol Prog Ser 149:23-34

Limpus CJ, Miller JD (2000) Australian hawksbill population dynamics project. Technical Report. Queensland Department of Environment and Heritage, Brisbane

Limpus CJ, Reed PC (1985) The green turtle, Chelonia mydas, in Queensland: a preliminary description of the population structure in a coral reef feeding ground. In: Grigg $G$, Shine R, Ehmann H (eds) Biology of Australasian frogs and reptiles. Royal Zoological Society of New South Wales, Sydney, p 513-523

Limpus CJ, Couper CJ, Read MA (1994) The green turtle, Chelonia mydas, in Queensland: population structure in a warm temperate feeding area. Mem Queensl Mus 35: 139-154

Loop KA, Miller JD, Limpus CJ (1995) Nesting by the hawksbill turtle (Eretmochelys imbricata) on Milman Island, Great Barrier Reef. Aust Wildl Res 22:241-252

Nietschmann B (1981) Following the underwater trail of a vanishing species - the hawksbill turtle. Natl Geog Soc Res Rep 13:459-480

Pilcher NJ, Ali L (1999) Reproductive biology of the hawksbill turtle, Eretmochelys imbricata, in Sabah, Malaysia. Chelonian Conserv Biol 3:330-336

Robins JB (1995) Estimated catch and mortality of sea turtles from the East Coast otter trawl fishery of Queensland, Australia. Biol Conserv 74:157-167

Scott R, Marsh R, Hays GC (2011) Life in the really slow lane: loggerhead sea turtles mature late relative to other reptiles. Funct Ecol 26:227-235

Troeng S, Chaloupka M (2007) Variation in adult annual survival probability and remigration intervals of sea turtles. Mar Biol 151:1721-1730

Velez-Zuazo X, Ramos WD, van Dam RP, Diez CE, AbreuGrobois AG, McMillan OW (2008) Dispersal, recruitment and migratory behaviour in a hawksbill sea turtle aggregation. Mol Ecol 17:839-853

Walker TA (1994) Post-hatchling dispersal of sea turtles. In: James R (ed) Proceedings of the Australian Marine Turtle Conservation Workshop, Gold Coast 14-17 November 1990. Australian Nature Conservation Agency, Canberra

Whiting SD, Guinea ML (1998) A large population of slow growing hawksbills: preliminary results from a wild foraging population in Fog Bay, Northern Territory. In: Epperly SP, Braun J (eds) 17th Annual Symposium on Sea Turtle Biology and Conservation. NOAA Tech Memo NMFSSEFSC-415, Miami, FL, p 104-107

Witzell WN (1983) Synopsis of biological data on the hawksbill turtle Eretmochelys imbricata (Linnaeus, 1766). Food and Agriculture Organisation of the United Nations, Rome Witzell WN, Banner AC (1980) The hawksbill turtle (Eretmochelys imbricata) in Western Samoa. Bull Mar Sci 30:571-57

Submitted: September 7, 2011; Accepted: November 4, 2011 Proofs received from author(s): January 19, 2012 